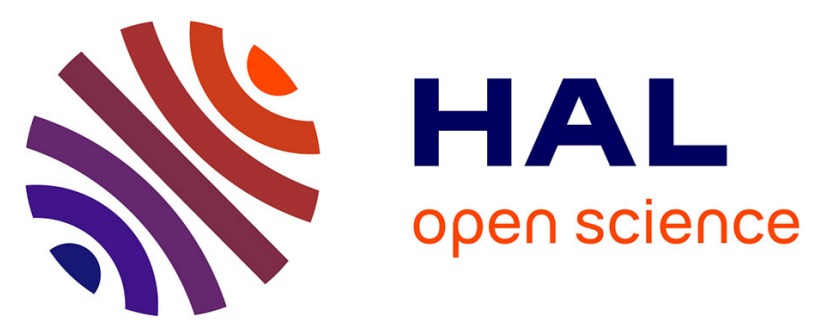

\title{
Paragangliomas of the spine: a retrospective case series in a national reference French center.
}

Constantin Tuleasca, Ahmed Salim Al-Risi, Philippe David, Clovis Adam, Nozar Aghakhani, Fabrice Parker

\section{- To cite this version:}

Constantin Tuleasca, Ahmed Salim Al-Risi, Philippe David, Clovis Adam, Nozar Aghakhani, et al.. Paragangliomas of the spine: a retrospective case series in a national reference French center.. Acta Neurochirurgica, In press, 10.1007/s00701-019-04186-8 . hal-02433449

\section{HAL Id: hal-02433449 https://hal.sorbonne-universite.fr/hal-02433449}

Submitted on 9 Jan 2020

HAL is a multi-disciplinary open access archive for the deposit and dissemination of scientific research documents, whether they are published or not. The documents may come from teaching and research institutions in France or abroad, or from public or private research centers.
L'archive ouverte pluridisciplinaire HAL, est destinée au dépôt et à la diffusion de documents scientifiques de niveau recherche, publiés ou non, émanant des établissements d'enseignement et de recherche français ou étrangers, des laboratoires publics ou privés. 


\title{
Paragangliomas of the spine: a retrospective case series in a national reference French center
}

\author{
Constantin Tuleasca ${ }^{1,2,3,4,5}$, MD-PhD, Ahmed Salim Al-Risi ${ }^{1}$, MD, Philippe David ${ }^{1}$, MD, Clovis \\ Adam $^{6}$, MD, Nozar Aghakhani ${ }^{1}$ AND Fabrice Parker ${ }^{1}, \mathrm{MD}, \mathrm{PhD}$ \\ ${ }^{1}$ Assistance Publique-Hôpitaux de Paris, Hôpitaux Universitaires Paris-Sud, Centre Hospitalier Universitaire \\ Bicêtre, Service de Neurochirurgie, Paris, France; ${ }^{2}$ Sorbonne Université, Faculté de Médecine; ${ }^{3}$ Centre \\ Hospitalier Universitaire Vaudois (CHUV), Neurosurgery Service and Gamma Knife Center, Lausanne, \\ Switzerland; ${ }^{4}$ Signal Processing Laboratory (LTS 5), École Polytechnique Fédérale de Lausanne (EPFL), \\ Switzerland; ${ }^{5}$ University of Lausanne, Faculty of Biology and Medicine; ${ }^{6}$ Laboratoire de neuropathologie, GHU \\ Paris-Sud-Hôpital Bicêtre, Le Kremlin Bicêtre, France
}

\section{Corresponding author:}

Constantin Tuleasca, MD-PhD, Assistance Publique-Hôpitaux de Paris, Hôpitaux Universitaires ParisSud, Centre Hospitalier Universitaire Bicêtre, Service de Neurochirurgie, Paris, France; Sorbonne Université, Faculté de Médecine; Centre Hospitalier Universitaire Vaudois, Neurosurgery Service and Gamma Knife Center, Rue du Bugnon 44-46, BH-08, CH-1011, Lausanne, Switzerland;

Tel: +41-21-314-26-02; Fax: +41-21-314-11-99; e-mail: constantin.tuleasca@,chuv.ch, constantin.tuleasca@gmail.com 


\begin{abstract}
Introduction:

Primary paragangliomas (PG) of the spine are extremely rare entities. The present study reviews our experience over a period of 30 years.
\end{abstract}

\title{
Methods:
}

This is a retrospective, single center, observational study. Patients treated for a spinal PG with confirmed anatomopathological diagnosis were included. The McCormick classification was used as a reference for clinical evaluation. Follow-up MRI and clinical assessment took place at 6 weeks, 3 months, 6 months and one year after surgery and on yearly basis after.

\section{Results:}

Six cases have been operated in our institution. The mean age was 37.8 (median 35.5, 30-53). The mean follow-up period was 9.6 years (median 9.5, 1-23). Preoperative duration of symptoms varied between a few hours to 4 years. Low back pain was most common sign. One presented with hemorrhage and acute onset of paraplegia. All patients underwent single surgery, with the exception of one case, which had two surgeries on the same anatomical site and a third surgery on another location of the same tumor type. Preoperatively, McCormick scale was I in four cases, and II and IV in one case, respectively. Postoperatively, all patients in McCormick I retained the same class; one patient in McCormick II passed to McCormick III; the case in McCormick IV recovered to McCormick II. Five of eight surgeries achieved total resection, while two surgeries accomplished a partial microsurgical excision and one a gross total resection. Three patients had spinal leptomeningeal dissemination. Two of them benefited from extended spine radiotherapy, while the other of a "wait-and-scan" policy. Spinal leptomeningeal dissemination was stable in all patients at last follow-up.

\section{Conclusion:}

We consider surgery as primary treatment in all PG. In our experience, preoperative diagnosis is difficult and caution must be taken to perioperative course in these cases. We do not routinely perform postoperative radiation if there is a residual tumor. We regularly perform clinical and radiological follow-up, so as to be able to document recurrent cases, which have been reported even up to 30 years after primary surgical excision. 


\section{Introduction}

Paragangliomas (PG) originate from the autonomous system (sympathetic secreting catecholamine or parasympathetic non-secretory), classically in adrenal and extra-adrenal locations[5]. At the level of the central nervous system, the vast majority are found in the jugular glomus, as well as the carotid bodies (approximately 90\% of them)[22]. Other locations could comprise pineal and pituitary glands or the cerebellopontine angle[7]. They might also be found in the orbit, larynx, liver, duodenum or retroperitonem, adventia of the abdominal aorta etc[20].

Primary PG of the spine are an extremely rare neoplasm[1]. Due to the sparse literature, there is no precise data on their prevalence. The peak of incidence is in the 5-th decade, with male predominance[11]. Clinical presentation is largely non-specific[8]. Most cases are located extramedullary and intradural. The classical anatomical site is cauda equina and filum terminale $[1,4,14]$. Other possible locations include extradural space, usually at the cervical and dorsal level, but are extremely rare[19]. They are classified as World Heath Organization (WHO) Grade I tumors, due to their slow growth and histologically benign appearance. Aggressive behavior is observed in less than $1 \%$ of tumors[14]. The first described case was in the early 70s, by Lerman et al., and defined as a "secretory ependymoma"[16]. More than 200 cases have been reported, up-to-date[18], with a vast majority of them located at the level of the cauda equina. Although the source of spinal PG as primary site remains somewhat unclear, Sundgren et al. suggest an origin in the sympathetic neurons in the thoracic and lumbar lateral horns of the spinal cord or heterotopic neurons, which lie along these branches proximal to the sympathetic trunk[23].

Due to the rarity of PG at the level of the spine, little is known about this disease. Primary treatment remains complete surgical resection, with preservation of the surrounding nerve roots. However, in the current literature, there is a gap of knowledge with regards to several aspects. Firstly, preoperative diagnosis by magnetic resonance imaging (MRI) remains challenging. In particular, differentiating between PG and other tumors remains difficult, with a further impact on the microsurgical strategy. Secondly, the role of preoperative embolization is controversial. Thirdly, there is a lack of long-term follow-up, as the few reports have limited observation periods, which usually do not overpass 8 years (at the best) for case series[28]. Hence, the fourth issue whether these tumors, despite their benign character, might recur or not, or might regrow in case of postoperative residue. A last aspect is whether or not residual PG should be irradiated and at what moment. The same issue would apply for appearance of leptomeningeal dissemination. 
Here, we detail clinical and radiological postoperative course up to 23 years later, in the frame of a multidisciplinary approach. In a previous report from our center back in 1999, we detailed our management on two cases of the cauda equine region[1]. In the present report, we share an update of our experience on 6 cases in a French reference center, over a period of 30 years.

\section{Methods}

\section{Patient population and selection}

This is a retrospective, single center observational study. All patients had been diagnosed and treated in our reference center for spinal neoplasms (CHU Bicêtre, Neurosurgery Service, Paris, France), over a period of 30 years.

The local Ethics Committee of the Assistance-Publique Hopitaux de Paris, CHU de Bicêtre approved our case review.

Inclusion criteria were: patients operated for a PG at the level of the spine, with confirmed anatomopathological diagnosis by one of the co-authors (AC, anatomopathologist).

Exclusion criteria were: refusal or inability to understand and sign informed consent.

After cross matching between the surgeons (NA, FP) patient's list and the anatomopathologist one, we retained for further analysis a number of 6 cases, which benefitted from 8 surgeries. Four cases were males and two were females. The mean age at diagnosis was 37.8 (median 35.5, range 30-53).

All have been discussed in board meetings including, beside the neurosurgical staff, a radiation oncologist, a neuroradiologist and the anatomopathologist.

\section{Preoperative and postoperative investigations}

The paraclinical preoperative check-up included detailed investigations. Pre- and postoperative magnetic resonance imaging (MRI, figure 1) was performed in all cases. Moreover, biological evaluation of vanilymandelic acid checked out the presence of eventual catecholamine secreting tumors, once the diagnosis of PG was established.

Peroperative course:

We do not routinely perform IOM for these type of tumors, nor for medullary tumors in general. 


\section{Clinical assessment}

The McCormick classification was used as a reference for the clinical evaluation, both preoperatively and postoperatively[17].

\section{Follow-up evaluation}

Follow-up MRI and clinical evaluation took place at 6 weeks, 3 months, 6 months and one year after surgery and on yearly basis after.

\section{Results}

\section{Basic demographic data}

The mean follow-up period was 9.6 years (median 9.5, range 1-23).

Low back pain was the most common symptom. For a more detailed review of the preand postoperative symptoms please refer to table 1 . Preoperative duration of symptoms varied between a few hours to 4 years. All cases had one surgery, with the except of case 1 (for details please refer to table 1), who had two surgeries on the same anatomical site and a third surgery on another location of the same type of tumor. We finally report on 6 cases and 8 surgeries.

The classical anatomical location was filum terminale (figure 1, left, illustrative case 1). For further details, please refer to table 1.

\section{Preoperative clinical status}

Preoperatively, McCormick classification was I in four cases, and II and IV in one case, respectively.

\section{Preoperative MRI assessment}

Magnetic resonance imaging in all the patients, with one exception (please see below) showed a contrast enhancing, well-circumscribed, intradural extramedullary tumor; this was hypointense or isointense on T1-weighted images and hyperintense on T2-weighted images. In chronological order, the first four cases were preoperatively diagnosed as either a schwannoma, meningioma or ependymoma, based on the MRI aspect. With regards to the last two cases and due to our experience, we considered them as being PG (see Discussion section).

One patient had a hemorrhagic lesion (Figure 1, center, illustrative case 2). 


\section{Intra- and postoperative course}

Elective posterior approach with laminectomy was performed in all cases. The intraoperative findings were classical, with the tensed, bulged dura. After opening the dura, we observed the reddish, friable mass (figure 2).

The unique hemorrhagic lesion had been also confirmed intraoperatively.

Five out of eight performed surgeries achieved total resection, while two surgeries accomplished a partial resection and one a gross total resection. In these former three cases, complete microsurgical excision was difficult, due to adherence to nerve roots of some specific tumor parts.

\section{Postoperative clinical status}

Postoperatively, all patients in McCormick I retained the same class.

One patient in McCormick II passed to McCormick III; the case in McCormick IV recovered to McCormick II.

\section{Patients with leptomeningeal dissemination}

Three patients had spinal leptomeningeal dissemination (figure 1, right, illustrative case 3 ; table 1).

After multidisciplinary discussion, two of them benefited from extended spine radiotherapy, while the other from a "wait-and-scan" policy (further stability for 12 years, the last follow-up time-point).

The spinal leptomeningeal dissemination was stable in all of them at last follow-up.

All patients were alive at last follow-up.

\section{Discussion}

In the present report, we detail our experience with spinal PG over a large period of time, up to 30 years. Due to the rarity of this condition, six cases have been treated in our institution.

As reported in the literature, clinical presentation in our series was also unspecific. Like in a recent systematic review[11], chronic lumbar pain was the most common symptom. Acute onset is usually associated with intralesional hemorrhage, which must be considered in such vascular tumors. In our practice, this was the case of one patient, further confirmed intraoperatively and by postoperative anatomopathological diagnosis. Preoperative hemorrhagic PG remains even more infrequent in the spine. Only isolated case reports 
revealed this type of lesion, with usually acute onset of preoperative paraplegia[10].

Preoperative radiological assessment is also vague and remains challenging. As reported in the literature, we always use preoperative MRI, which is considered as gold standard for diagnosis. Typically, the former displays a sharply confined infrequently cystic mass, hypo- or isointense to the spinal cord on T1-weighted images (isointense in approximately $76 \%$ of patients[11]), with an evident contrast enhancement (in around $60 \%$ of cases[11]), further hyper-intense on T2-weighted images. Despite these characteristics, one might easily confound them either with schwannomas, meningiomas or, more frequently, with ependymomas. In fact, in the present series, preoperative neuroimaging diagnosis was frequently schwannoma and meningioma or ependymoma. In our practice and retrospectively analyzing all these cases, we do consider that a "salt and pepper" aspect on T2 weighted imaging can be more characteristic of paragangliotic tumours. Moreover, in the presence of serpentine, ecstatic vessels, with a low signal intensity rim (so-called "cap sign") a PG can be suspected[27].

Other paraclinical investigations should include, in case of doubts, laboratory tests as mandatory, mainly by catecholamine evaluation, for avoidance of potential systemic complication, by labile hypertension. It is now well acknowledged that vanilymandelic acid and metanephrine can act as tumor markers for the secretory entities[2]. During time, for two cases, we did perform these tests preoperatively, as the MRI was potentially suggestive for PG. They revealed negative every time.

One opened question is whether or not to use preoperative embolization. In our experience, we do not routinely use this technique to reduce bleeding risks. The indications of such procedure are, in our practice, limited. There might be a role of embolization in secreting cases, to diminish the vascular and biological load.

Primary treatment is complete microsurgical resection. Peroperatively, PG are usually soft, red and well-circumscribed masses (figure 2). They habitually grow from the filum terminale, while less commonly from the nerve root. They further might be attached to the conus medullairs or adherent to nerve roots, or to a vascular pedicle. Their separation may be difficult or sometimes impossible. Frequently the tumor is, however, well encapsulated, with total removal being easily accomplished.

In the postoperative setting, it is recommended to perform regular clinical and radiological follow-up. Although they are slow growing tumors, we do consider that there is a possibility of relapse even 30 years after microsurgical resection[6]. Annual MRIs are, in our opinion, mandatory, as these tumors might recur several years after initial microsurgical 
resection.

The place of radiosurgery (RS) versus radiotherapy (RT) as first intention or as an adjuvant treatment for spinal PG remains a matter of debate. As they are considered WHO I neoplasms, the literature is contradictory on this issue. Our policy is not to routinely perform an adjuvant treatment, if gross total resection is achieved. However, in the present series, focal radiotherapy was performed in two cases. In one of them, this was applied as a focal treatment from D7 to S3, due to reintervention for focal recurrence 32 months after previous surgery. In another case, spinal RT had been done due to major and diffuse leptomeningeal dissemination. During follow-up course, MRI showed stable course in both cases. Another case with leptomeningeal dissemination, including at cervical level, benefited from a "waitand-scan" policy, with further stability up to 12 years. Single-fraction RS has already been documented in the literature by the historical series of Gerszten et al.[9], who described 15 cases of spinal tumors who benefited from Cyberknife RS. The mean tumor dose was $16 \mathrm{~Gy}$ (range 12-18 Gy at the $80 \%$ isodose line). In this series, 3 patients had PG. No radiation induced toxicity or new neurological deficits occurred, while pain improved in all cases symptomatic prior to therapy. No tumor progression has been described after a mean followup of 12 months. Another case scenario might involve the combined management with surgery and RS in the presence of multiple lesions, including of cervical and paraphayringeal location[21]. Moreover, single-fraction RS could be also of benefit in case of secreting tumors, as already proven for the jugular locations[24]. External beam radiation therapy has also been reported, especially in the setting of malignant tumors[26], distant metastases[15] or metastatic disease[12].

Intraoperative neuromonitoring has been calsically considered of clinical importance in microsurgical resection of intramedullary spinal cord tumors. Several modalities are used, including somatosensory evoked potentials, transcranial motor evoked potentials via limb muscles or spinal epidural space (D-waves), and dorsal column mapping. Although we don't routinely use them in our center, we do consider that such adjunctive measures can inform the surgeon intraoperatively. They can further lead to changes in the operative decision. Moreover, they can improve the postoperative neurologic functioning and outcome of such patients[3, 13, 25].

Our study has several limitations. One is the retrospective nature of such review, with the inherent bias. A second is related to the small number of cases. However, despite being a reference French center, we only operated 6 cases during the past 30 years of our activity, due to the rarity of this condition. Other limitations are related to the long period of time spanning 
over 30 years. As such, a third limitation is related to the clinical evaluation, performed by different doctors. However, we tried to overwhelm this limitation by using the McCormick scale as a standard one. A fourth limitation is related to the neuroradiological MRI assessment, with sequences, which vary over time. This aspect is also relevant as it further allowed at the end of our series to more easily diagnose PG and differentiate them from other tumors. A fifth limitation is that some of the information might be lost. However, we have been very cautious and accessed the paper files also. Furthermore, these patients have been regularly seen in person with documented follow-up. A sixth limitation is related to eventual change in therapeutic paradigms during such a long period of time. However, in the particular case of these tumors, we continue to offer primarily surgical resection. Moreover, we have continued not to perform irradiation on the tumor remnant on routine basis.

\section{Conclusion}

We consider surgery as primary treatment in all cases. We do not routinely perform radiation if there is a residual tumor. In cases with leptomeningeal dissemination, each case is discussed separately in the frame of multidisciplinary meeting. In our experience, preoperative diagnosis is difficult and cautious must be taken to perioperative course in these cases. We regular perform clinical and radiological follow-up, so as to be able to document any eventual recurrence and/or disease progression or leptomeningeal dissemination, which have been reported even up to 30 years after primary surgical excision. 


\section{Tables}

Table 1: Demographic data

\section{Figures}

Figure 1: illustrative case 1,2 (with intralesional hemorrhage); both pre- and postoperative images are shown, in the sagittal plane; in illustrative case 1 it is shown a 30 -years old male, presenting with low back pain, sometimes irradiating on his left foot and lasting over the past year and unremarkable neurological exam; lumbar MRI showed what was considered spinal neurinoma by the neuroradiologist, but we did not exclude the possibility of a PG; monobloc microsurgical complete resection was feasible and anatomopathological diagnosis revealed PG with Ki67 of $8 \%$; the postoperative neurological exam remained unremarkable and follow-up MRI up to 2 years showed no recurrence; in illustrative case 2 it is shown 36-years old male presenting with tailbone pain during the past 4 months, and further acute pain in both inferior limbs, while having difficulty in ambulation; neurological exam revealed a bilateral L5 root deficit quoted at 2/5; preoperative MRI displayed compression of the cauda equina by a L1-L3 lesion, compatible with a hematoma (descending down to the sacrum) versus intralesional hemorrhage; intraoperative exploration made difficult to evaluate if there was only hematoma versus presence of tumor tissue; anatomopathological diagnosis was PG; postoperative neurological exam was marked by strength recovery (from M2 to M4), with persistence of gait problems and follow-up MRI up to 7 years revealed no recurrence. illustrative case 3 (leptomeningeal dissemination at the lumbar level);

Figure 2: intraoperative appearance 


\section{Compliance with Ethical Standards: yes}

Funding: Funding: Constantin Tuleasca gratefully acknowledges receipt of a 'Young Researcher in Clinical Research Grant' (Jeune Chercheur en Recherche Clinique) from the University of Lausanne (UNIL), Faculty of Biology and Medicine (FBM) and the Lausanne University Hospital (CHUV)

Conflict of interest: All authors certify that they have no affiliations, with or involvement in any organization or entity with any financial interest (such as honoraria; educational grants; participation in speakers' bureaus; membership, employment, consultancies, stock ownership, or other equity interest; and expert testimony or patent-licensing arrangements), or non-financial interest (such as personal or professional relationships, affiliations, knowledge or beliefs) in the subject matter or materials discussed in this manuscript.

Ethics approval: Ethical Committee Approval has been required, according to the French rules, at the Assistance Publique, Hopitaux de Paris, Paris, France for this retrospective review of cases. 


\section{References:}

1. Aghakhani N, George B, Parker F (1999) Paraganglioma of the cauda equina region--report of two cases and review of the literature. Acta neurochirurgica 141:81-87 2. Akhtar S, Sattar S, Bari E, Kayani N, Moeen S (2016) Secretory paraspinal paraganglioma of thoracolumar spine: Case report and review of literature. Surgical neurology international 7:S889-S892

3. Albright AL (1998) Intraoperative spinal cord monitoring for intramedullary surgery: an essential adjunct? Pediatric neurosurgery 29:112

4. Anderson JR, Gullan RW (1987) Paraganglioma of the cauda equina: a case report. Journal of neurology, neurosurgery, and psychiatry 50:100-103

5. Caruso R, Wierzbicki V, Marrocco L, Salvati M (2006) Paragangliomas of the cauda equina. Report of one case and review of the literature. Journal of experimental \& clinical cancer research : CR 25:269-275

6. Corinaldesi R, Novegno F, Giovenali P, Lunardi T, Floris R, Lunardi P (2015) Paraganglioma of the cauda equina region. The spine journal : official journal of the North American Spine Society 15:e1-8

7. Deb P, Sharma MC, Gaikwad S, Gupta A, Mehta VS, Sarkar C (2005)

Cerebellopontine angle paraganglioma - report of a case and review of literature. Journal of neuro-oncology 74:65-69

8. dos Santos MP, Zhang J, Ghinda D, Glikstein R, Agid R, Rodesch G, Tampieri D, terBrugge KG (2015) Imaging diagnosis and the role of endovascular embolization treatment for vascular intraspinal tumors. Neurosurgical focus 39:E16

9. Gerszten PC, Ozhasoglu C, Burton SA, Welch WC, Vogel WJ, Atkins BA, Kalnicki S

(2003) CyberKnife frameless single-fraction stereotactic radiosurgery for tumors of the sacrum. Neurosurgical focus 15:E7

10. Ghedira K, Matar N, Bouali S, Zehani A, Jemel H (2019) Acute Paraplegia Revealing a Hemorrhagic Cauda Equina Paragangliomas. Asian journal of neurosurgery $14: 245-248$

11. Honeyman SI, Warr W, Curran OE, Demetriades AK (2019) Paraganglioma of the Lumbar Spine: A case report and literature review. Neuro-Chirurgie 12. Jia Q, Yin H, Yang J, Wu Z, Yan W, Zhou W, Yang X, Xiao J (2018) Treatment and outcome of metastatic paraganglioma of the spine. European spine journal : official publication of the European Spine Society, the European Spinal Deformity Society, and the European Section of the Cervical Spine Research Society 27:859-867

13. Kothbauer K, Deletis V, Epstein FJ (1997) Intraoperative spinal cord monitoring for intramedullary surgery: an essential adjunct. Pediatric neurosurgery 26:247-254 14. Landi A, Tarantino R, Marotta N, Rocco P, Antonelli M, Salvati M, Delfini R (2009) Paraganglioma of the filum terminale: case report. World journal of surgical oncology 7:95

15. Lehmen JA, Babbel DM, Mikhitarian K, Choma TJ (2010) Paraganglioma presenting as metastatic lesion in a cervical vertebra: a case report and review of the literature. Spine 35:E152-154

16. Lerman RI, Kaplan ES, Daman L (1972) Ganglioneuroma-paraganglioma of the intradural filum terminale. Case report. Journal of neurosurgery 36:652-658

17. McCormick PC, Stein BM (1990) Intramedullary tumors in adults. Neurosurgery clinics of North America 1:609-630 
18. Mishra T, Goel NA, Goel AH (2014) Primary paraganglioma of the spine: A clinicopathological study of eight cases. Journal of craniovertebral junction \& spine 5:2024

19. Ojha BK, Sharma MC, Rastogi M, Chandra A, Husain M, Husain N (2007)

Dumbbell-shaped paraganglioma of the cervical spine in a child. Pediatric neurosurgery 43:60-64

20. Park HK, Han HS (2016) Duodenal Gangliocytic Paraganglioma With Lymph Node Metastasis. Archives of pathology \& laboratory medicine 140:94-98

21. Sasaki K, Inose H, Kawabata S, Yoshii T, Kato T, Saito M, Okawa A (2013)

Combined surgical and radiosurgical treatment for a symptomatic cervical metastasis in a case of malignant paraganglioma: a case report. BMC research notes 6:494

22. Suarez C, Rodrigo JP, Bodeker CC, Llorente JL, Silver CE, Jansen JC, Takes RP, Strojan P, Pellitteri PK, Rinaldo A, Mendenhall WM, Ferlito A (2013) Jugular and vagal paragangliomas: Systematic study of management with surgery and radiotherapy. Head \& neck 35:1195-1204

23. Sundgren P, Annertz M, Englund E, Stromblad LG, Holtas S (1999)

Paragangliomas of the spinal canal. Neuroradiology 41:788-794

24. Tuleasca C, Jaquet Y, Schweizer V, Negretti L, Magaddino V, Maeder P, Abid KA, Lhermitte B, Grouzmann E, Levivier M (2016) Clinical and biochemical responses after Gamma Knife surgery for a dopamine-secreting paraganglioma: case report. Hormones 15:106-112

25. Verla T, Fridley JS, Khan AB, Mayer RR, Omeis I (2016) Neuromonitoring for Intramedullary Spinal Cord Tumor Surgery. World neurosurgery 95:108-116

26. Vogel J, Atanacio AS, Prodanov T, Turkbey BI, Adams K, Martucci V, Camphausen K, Fojo AT, Pacak K, Kaushal A (2014) External beam radiation therapy in treatment of malignant pheochromocytoma and paraganglioma. Frontiers in oncology 4:166

27. Yang SY, Jin YJ, Park SH, Jahng TA, Kim HJ, Chung CK (2005) Paragangliomas in the cauda equina region: clinicopathoradiologic findings in four cases. Journal of neurooncology 72:49-55

28. Yin M, Huan Q, Sun Z, He S, Xia Y, Mo W, Ma J, Xiao J (2017) Clinical characteristics and surgical treatment of spinal paraganglioma: A case series of 18 patients. Clinical neurology and neurosurgery 158:20-26 